\title{
A Morphological Analysis of Akan Honorific and Title Names for God
}

\author{
Samuel Yeboah \\ Department of Ghanaian Languages and Linguistics, University of Cape Coast, Ghana \\ Emmanuel Amo Ofori \\ Department of Ghanaian Languages and Linguistics, University of Cape Coast, Ghana \\ Kofi Busia Abrefa \\ Department of Ghanaian Languages and Linguistics, University of Cape Coast, Ghana
}

\begin{abstract}
This study is motivated by our observation that earlier works have looked at Akan personal names either from sociolinguistics or non-linguistic perspectives; however, a critical morphological analysis of the structure of Akan honorific and title names for God has eluded researchers in linguistics. It is based on this background that we conduct a thorough morphological investigation into Akan honorific and title names for God, with the aim of addressing the morphological processes that account for their derivation. Drawing on data from both primary and secondary sources, the analysis reveals that Akan honorific and title names ascribed to God have complex nominals and this is manifested through affixation, compounding and reduplication. It further shows that some of the names are recursive in nature and are therefore derived through nominalization of sentences or clauses, especially those that undergo compounding.
\end{abstract}

Index Terms—morphology, Akan, honorific, title names, God

\section{INTRODUCTION}

African names may reflect the name-users' geographical environment as well as their fears, religious beliefs, and philosophies about life and death and this is evident in Akan. The names of children may even provide insights into important cultural or socio-political events at the time of their birth (Obeng, 2001). Many Scholars (e.g. Opoku, 1967; Ansu-Kyeremeh, 2000; Obeng, 2001; Agyekum, 2006, etc.) have strived to classify Akan personal names into various kinds. However, the focus of this study is based on the typology outlined by Agyekum (2006) as it arguably projects almost all the aspects of Akan personal names. Agyekum (2006) gives the typology of Akan personal names including, birthday names, family names, circumstantial names, flora and fauna, and physical structure names, theophoric names, insinuating, proverbial, insults and nicknames, gang, play and occupational names, and honorific and title names.

Agyekum (2006) describes honorific and title names, the focus of this paper, as names that are achieved outside people's given names. Such names are normally appellations and titles which may be achieved from occupations, wars, zeal, and stool names when a person is enthroned. Jkogyeasuo "the fighter who seizes rivers", Bediako "came to engage in wars" etc. are some of the examples of this category of Akan personal names. Names in this category are used in diverse social contexts and their usage portrays the Akan deference for their addressees (Yankah, 1995; Agyekum, 2003). That is to say, honorific and title names could mostly be employed in Akan formal settings to probably serve as a persuasive mechanism among interlocutors (Obeng, 1997; Agyekum, 2004). These names are normally ascribed to the elites and the powerful in the society including natural and supernatural entities (Boadi, 1989; Amekpordi, 2012).

The honorific and title names ascribed to God in Akan for instance, reflects the belief of the speakers in this Supreme Being (Mbiti, 1991). In other words, it is observed that the Akan honorific and title names attributed to the Supreme God capture the Akan ideology, philosophy, worldview and thought about the Supreme God. For example, the Akan

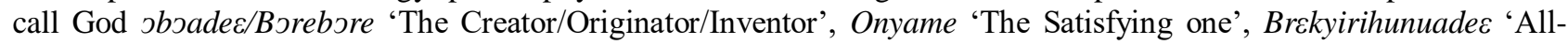
knowing', sdomankoma 'The Passionate one', skofo(ว) 'The Warrior', Otwereduampon/Tweaduampэn, 'The Dependable'etc. (see Christaller, 1933; Danquah, 1968; Agyekum, 2003; Ansong, Asante \& Kquofi, 2014).

In Akan, there are various types of honorifics used in different social contexts. They include: power-based, genderbased, occupational and symmetrical solidarity honorifics (Agyekum, 2003). This paper is particularly concerned about the power-based honorifics which are honorific expressions ascribed to an addressee based on his/her power or the social class, age, profession, gender, etc. The power-based honorifics are always asymmetric and nonreciprocal; that is, such honorifics always come from a subordinate to a superior but not vice versa. Most of the honorifics ascribed to God in Akan are power-based. Such honorifics express God's omnipotence, omnipresence, his amazing grace, generosity

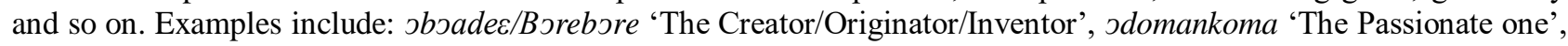
Otwereduampcn/Tweaduampon, and among others. Apart from these power-based honorifics, the Akan occasionally 
ascribe other types of honorifics including gender-based, occupational-based and solidarity honorifics to God such as sbaatan-pa 'good mother', ssahene 'commander-in-chief' and Agya 'father' respectively.

As Boadi (1989), Anyidoho (1991), and Agyekum (2003) note, Akan honorific and title names which are normally in the form of appellations may be grammatically complex in that their formation mostly involves putting morphemes or words together to form compound-names, or agglutination of sentences or clauses which sometimes make their interpretation very challenging. This paper, seeks to add to the growing body of research on Akan personal names by gearing the analysis towards the morphology of Akan honorific and title names for God (AHTN-G). That is, the study aims at describing the various word formation processes that take place during the nominalization of the names for God in Akan.

\section{The Akan concept of God}

Before the European Christian Missionaries came to Africa in the seventeenth and eighteenth centuries, the idea of God as a Supreme Being was already known and held by the people (Mbiti, 1991). Sarpong (1974) shares this view by postulating that if the Ghanaian concept of God had been borrowed from the missionaries, it would hardly have been possible for it to have been so well impressed on the minds of the people, and incorporated into their language, art, poetry, proverbs, day-to-day behaviour and drumming as we have had occasion to explain. As a matter of fact, all the three main religions (African Traditional Religion, Christian Religion and Islamic Religion) which have emerged in Africa and for that matter Ghana, have a common belief that there is a Supreme Being — God - who created all things in the universe and therefore, very powerful (Gyekye, 1996; Sarpong, 2011). As has been mentioned earlier, there are a lot of honorific and title names ascribed to God to show how the Akan conceive of Him.

It is worth noting that aside from the above, there are certain cultural practices as well as social activities among the Akan which similarly depict their worldview about God, the Supreme Being. Ansong et.al (2014) note that names, appellations, proverbs and idioms ascribed to the Supreme Being show how unique and distinct He is from other deities. For instance, names like Nyame dua "God's tree", Nyankonsuo "God's water" (rainwater), Nyankonton "God's bow" (rainbow) etc, bring to bear, their belief or idea about the Supreme Being (Rattary, 1927; Danquah, 1968). Likewise, Akan maxims like "If you want to talk to God, talk to the wind" depict their knowledge about God. The wind blows everywhere and, in all directions, although no one sees and touches it, its effects are felt everywhere. Similarly, to the Akan, God is everywhere just like the wind; and this depicts His Omnipresence.

\section{Data Collection Procedure}

The data was gathered from both primary and secondary sources. The primary source was ascertained by using two main research instruments namely, interviewing and observation while data from the secondary source was retrieved from documented materials such as books, articles, thesis (both published and unpublished), among others. Some examples of documented materials which were very useful source of data collection include the Akan Dictionary by J. G. Christaller, and Asante-Twi Bible published by The Bible Society of Ghana.

In all, eighteen speakers living in the Ashanti Region, Kumasi and Wiamoase to be precise and two Akan-Twi lecturers, were purposively sampled for the study. The choice was not only motivated by demographic features such as age and social status or position but also on the basis of their empirical knowledge on the Akan honorific and title names explored in the study. It is important to point out that none of these informants was below the age of fifty. Moreover, out of these twenty participants, twelve were males and eight, females. Two of the participants were reverend ministers; four were traditional priests/priestesses; two of them were curators (both former and present) of The Manhyia Palace; and two were Akyeame (spokespersons). Out of the remaining ten, eight were among other traditional rulers (a chief, a queen mother, a clan head and a sub-chief). The last two participants were lecturers from the University of Cape Coast, Department of Ghanaian Languages and Linguistics.

\section{ANALYSIS AND DISCUSSION}

This section analyses and discusses some of the various morphological processes involved in the formation of Akan honorific and title names for God. A closer look at the data collected for the study reveals the following morphological processes in the derivation of the names of God: affixation, compounding and reduplication. In general, the structure of AHTN-G is mono-morphemic, di-morphemic or poly-morphemic. The next subsection looks at the mono-morphemic names identified in the study.

\section{A. Deriving AHTN-G from Single Root Morphemes}

AHTN-G in this category are composed of free morphemes whose internal morphological structures cannot be broken down into further morphemes to derive meaningful forms. This implies that the names are non-derivable and therefore have covert affixal markings. The names, made up of single roots, mostly carry the major components of their meanings. Moreover, the names under this umbrella may be arbitrary labels referring to God in a metaphorical sense. Examples of such names include Kurotwiamansa 'Leopard', Prekese 'Aidan fruit', Kokurobeti 'the Thumb' and Poma 'Walking stick'. None of these AHTN-G is decomposable. 
As could be seen from the examples above, the names are mono-morphemic in that they are semantically impossible when an attempt is made to break them into further morphemes. It could also be seen that all the nouns above are common nouns that have been metaphorically extended to God; and that when any of them is put in context, it becomes more meaningful than in isolation. In other words, the Akan socio-cultural factors that hinge on the names in this category become more explicit when they are situated in contexts. For example, the expression Mede Onyame beys me poma daa nyinaa 'I will always make God my walking stick'. This implies that God is a Helper and therefore should be consulted in all matters. There is also an appellation of God which goes like this: Prekese Gyamaadu a Jiti kurotia reba a na ne ho agye afie mu 'The Prekese Gyamaadu whose aroma is diffused into houses prior to His entry into a neighbourhood'. This also implies that God is believed to exist and that His presence is always felt although not physically seen. It may also connote His might and wondrous nature. All the above names thus express a complete thought about God among the Akan.

\section{B. Deriving AHTN-G through Affixation}

Another process through which some of these AHTN-G are derived is affixation. That is, attachment of an affix (prefix, suffix or both) to a base to derive other forms distinct from the underlying constituents. Here, the study reveals three lexical categories from which the names are derived. These lexical categories are verbs, adjectives and nouns. Let us first consider how the names of God are derived through verbal nominalization.

\section{Deriving AHTN-G from Verbs}

Appah (2003) remarks that the nominalization of verbs is a type of nominal derivation that has been attested in almost all existing languages. Generally, the simple formula $\mathrm{V} \rightarrow \mathrm{N}$ can assist us in deriving the nominals from verbs as exemplified in the table below:

TABLE 1

AHTN-G DERIVED FROM VERBS

\begin{tabular}{|c|c|c|c|c|c|c|}
\hline \multicolumn{2}{|c|}{ Prefix } & Root/ & Gloss & Suffix & Derived form & Gloss \\
\hline i. & 5- & do & love & - & odo & Love \\
\hline ii. & 5- & dom & help & -for & Jdomfor & Gracious One \\
\hline iii. & 5- & hwe & look & - for & Jhwefo & Shepherd \\
\hline iv. & 5- & gye & save & -for & Jgyefo & Refuge \\
\hline
\end{tabular}

It could be observed from the data above that some bound morphemes have been attached to the free forms (which are verbs) to derive the names. It is worth mentioning also that apart from example (i) the derivational morphemes in the examples are the suffixes. The prefixes are inflectional morphemes, indicating number. The derivation processes can be captured by the following sub-lexical rules below:

$1 . \mathrm{N} \rightarrow$ Pfx-Verb $_{\text {base }}-(\mathrm{Sfx})$

2. a

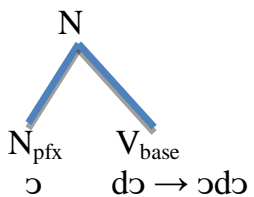

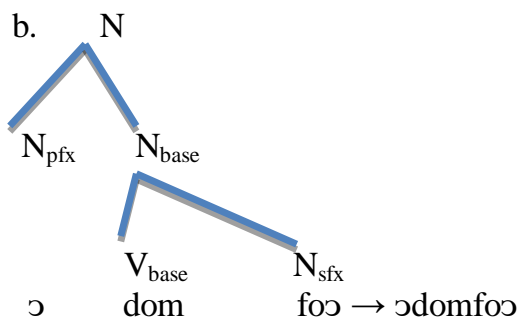

It could be observed from ( $2 \mathrm{a}$ ) that the verb $d \supset$ 'to love', constituting the base is attached to the nominal prefix [ว-] to derive the noun $J d \supset$ 'Love'. In $2 \mathrm{~b}$, the base dom 'help', first merges with the nominalised suffix [-foכ] to form a complex/larger base before it merges with the inflectional affix [ว-] to complete the nominalization process to form the name sdomfoj.

\section{Deriving AHTN-G from Adjectives}

Some of the names of God are also derived from adjectives. In other words, nominal affixes are attached to adjectives to derive such nouns as exemplified below:

TABLE 2

AHTN-G DERIVED FROM ADJECTIVES

\begin{tabular}{|c|c|c|c|c|c|}
\hline Pfx & Root/Stem & Gloss & Sfx & Derived form & Gloss \\
\hline i. $5-$ & kese $\varepsilon$ & big & - & 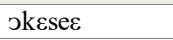 & The Great one \\
\hline ii. $5-$ & kantinka & huge & - & okantinka & The Great one \\
\hline iii. o- & kokuroko & great & - & Okokuroko & The Huge one \\
\hline iv. J- & kronkron & holy & $-n i$ & Jkronkronni & The Holy one \\
\hline
\end{tabular}


The derived forms reflect the augmentativeness of God. Like the nominal derivation of verbs, the nominalized adjectives may take either a prefix, a suffix or both, as could be seen from table 2 above. The sub-lexical rule for the derivation of the nominalized adjectives can be formulated as in (3) below:

3. $\mathrm{N} \rightarrow \mathrm{Pfx}_{\mathrm{Adj}} \mathrm{Adase}_{\mathrm{b}}-(\mathrm{Sfx})$

The rule is exemplified as follows:

4. a

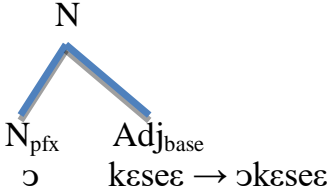

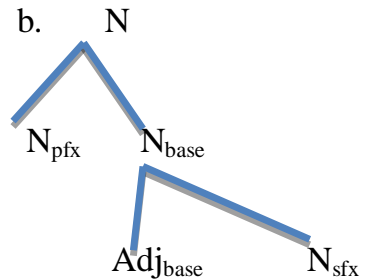

כ

Just like the nominalization of verbs, it can be observed from (4a) that the nominal prefix [0-] is attached to the adjective $k \varepsilon s e \varepsilon$ 'big' to yield the surface form $\jmath k \varepsilon s e \varepsilon$ 'the great one'. In (4b), however, the derivational affix [-ni] is first attached to the form kronkron 'holy' to form the structure kronkronni, before it merges with the singular marker [ว-] to form the name okronkronni 'The Holy one'. It is worth pointing out that the names within this category can also function like any proper noun (e.g. subjects/objects).

Sometimes some of these adjectives are converted to nouns without any overt affixes. They thus go through the process referred to as zero affixation or conversion. For instance, the adjectives $k \varepsilon s e(\varepsilon)$, kantanka, and punpuni may be converted to become personal names without any change in form.

\section{Deriving AHTN-G from Nouns}

Some of the AHTN-G derived from other nouns. Like the nominalization of adjectives and verbs, the names under this category possess affixes which mark number (singular) and agentive markers depicted below:

TABLE 3

AHTN-G DERIVED FROM NOUNS

\begin{tabular}{|c|c|c|c|c|c|}
\hline Pfx & $\begin{array}{l}\text { Stem/ } \\
\text { Base }\end{array}$ & Gloss & Sfx & Derived form & Gloss \\
\hline i. $5-$ & ad’ec & Kindness & - for & วdęfoว & Benevolent \\
\hline ii. $\mathrm{o}-$ & tumi & Power & - for & Otumfor & The Powerful one \\
\hline iii. $0-$ & ninkunu & Jealousy & - for & Oninkufo & The Jealous one \\
\hline iv. - & tenenee & righteousness & - ni & Jteneneeni & The righteous one \\
\hline
\end{tabular}

It should be noted that the suffixes $n i$ and for are agentive markers in this context; none of them is marking number (although in some other contexts they can mark number as well). It is rather the prefixes that are marking number (singular). The sub-lexical rule that derives these names can be schematized in (5) below:

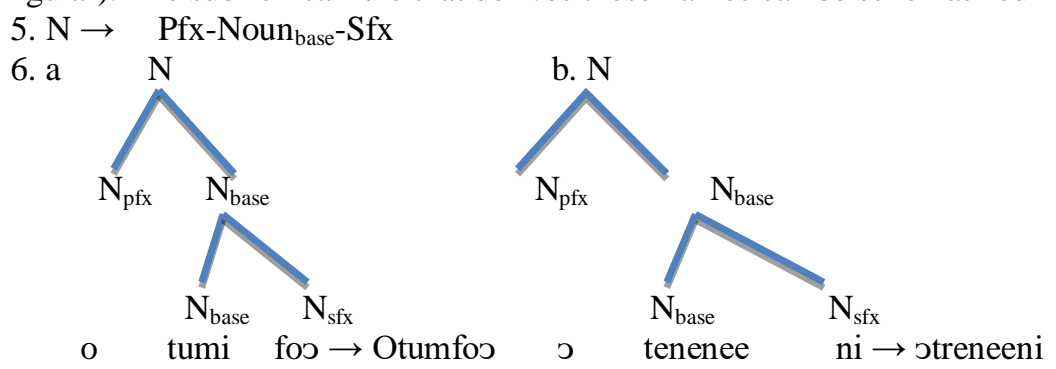

As we have observed before, the derivational affix is first attached to the base before the inflectional affix is attached to the complex base to form the name. It should also be noted that the base forms for these nouns are abstract in nature.

\section{Deriving AHTN-G through Compounding}

Compounding is one of the most productive word formation processes in Akan, just like in most other languages. Compounding, as a word formation process, aims at adjoining two or more lexical items or bases to produce new forms distinct from the underlying constituents. Majority of the data collected for the study fall under this process. The names in this domain are observed to have emanated from one of the following formal classifications of compounding: Noun + Noun, Noun + Verb, Noun + Adjective, Verb + Verb, Noun + Postposition + Noun etc. This is therefore in line with those outlined by scholars such as Dolphyne (1988), Abakah (2003), Owu-Ewie (2014), Appah (2013), among others. A closer look at the compound names also reveals instances where part of these nominals are nominalized sentences or clauses. That is, a whole or part of a sentence is fused together to form the names. Further, a compound nominal may either be in isolative (open), combinative (solid) or hyphenated style (Lieber, 2009; Hayes, 2009; Appah, 2013; OwuEwie, 2014; Agyekum, 2017). Also, the AHTN-G that are described from this angle are poly-morphemic. 


\section{Deriving AHTN-G from Noun + Noun Compounds}

This type of compounding is one of the productive word formation processes in Akan in general (Dolphyne, 1988; Abakah, 2004; Marfo, 2004; Appah, 2013). This is where two independent base nouns or noun phrases are combined in the process of deriving the name. In Noun-Noun compounding, mostly, the first noun (N1) serves as a pre-modifier to the second noun (N2). That is, the first nouns qualify the second nouns (i.e. appositive). Here, the N2 is thus the substantive noun being modified by the N1 at pre-head position. There are two types: those that are written together as one word, and those that are open even at the surface level as exemplify below:

TABLE 4

AHTN-G DERIVED FROM NOUN-NOUN COMPOUNDS

\begin{tabular}{|c|l|l|l|}
\hline \multicolumn{1}{|c|}{ Base forms } & Gloss & Derived form & Gloss \\
\hline i. ayeyie + owura & praise + lord & Ayeyiwura & Lord of praise \\
\hline ii. Jsa + Jhene & war + king & Jsahene & Warlord \\
\hline iii. onnibie + adamfo & 'the poor' + 'friend' & Onnibie Adamfo & The Friend of the Poor \\
\hline iv. akunafo + kunu & 'widows' +'husband' & Akunafoj Kunu & 'Widows' husband' \\
\hline
\end{tabular}

As could be seen from table 4 above, the underlying lexical items concatenated to form the nominals are made up of two independent nouns; and the resultant nouns are in combinative style. The first constituents modify the second constituents in all the cases. The sub-lexical rule for the derivation of N-N compound names can be formulated as in (7) below.

7. $\mathrm{N} \rightarrow$ Noun $_{\text {base }}-$ Noun $_{\text {base }}$

8. a

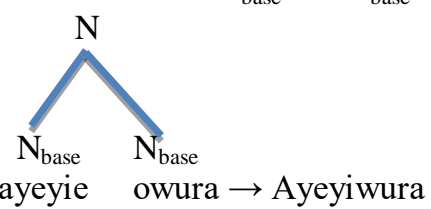

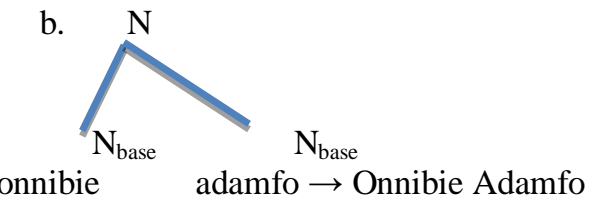

\section{Deriving AHTN-G from Noun + Adjective Compounds}

Some of the AHTN-G are derived from noun-adjective compounds. That is, the first word is a noun and the second, an adjective. The nouns in these constructions are head nouns (NPs) being modified by the adjectives in the post-head position. Adjectives in this category are used attributively as exemplified below:

TABLE 5

AHTN-G DERIVED FROM NOUN-ADJECTIVE COMPOUNDS

\begin{tabular}{|l|l|l|l|}
\hline \multicolumn{1}{|c}{ Base forms } & Gloss & Derived form & Gloss \\
\hline i. $\varepsilon$ ban + denden & wall + hard & Abandenden & Hard wall \\
\hline ii. nufo + tabraba & breast + large & Nufotabraba & The Large Breast \\
\hline iii. atofo + kese $\varepsilon$ & waist + mighty & Atofokese & The Mighty waist \\
\hline iv. dua + pon & tree + large & Odupon & The Great Tree \\
\hline
\end{tabular}

It could be observed from table 5 that apart from the example in (iv) none of the derived nominals has an inflectional affix. So far as the derivational process is concerned, the two bases first come together to form a complex base, then an affix (optional) could be attached to this complex base to complete the derivation process as seen in (10b). The sublexical rule for this process is schematized below:
9. $\quad \mathrm{N} \rightarrow$
10. a
$\overrightarrow{\mathrm{N}}$
(Pfx) Noun $_{\text {base }}-$ Adj $_{\text {base }}$

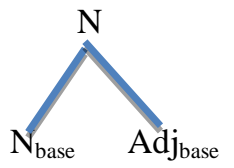
atofo $\quad \mathrm{k} \varepsilon \sec \varepsilon \rightarrow$ Atofokse $\varepsilon$

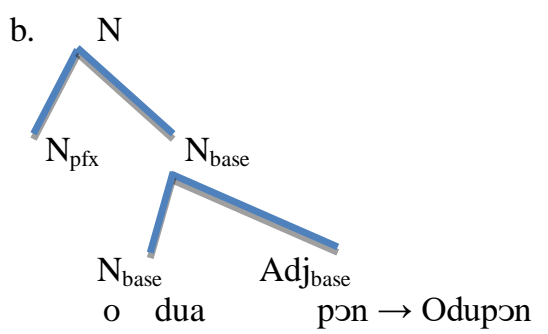

It could be observed from (10) that the derived nominal follows the syntactic structure of Akan where the adjective is the post modifier to the head-noun. Additionally, as said earlier, the adjectives qualifying the noun express physical property of God in metaphorical context or imaginary sense. The adjectives in the derived nominal mark augmentativity.

\section{Deriving AHTN-G from Noun + Verb Compounds}

In addition, some of the AHTN-G are derived from noun-verb compounds. The nouns precede the verbs even in the surface structure as depicted below. 
TABLE 6.

\begin{tabular}{|c|c|c|c|c|c|}
\hline Pfx & Base forms & Gloss & Sfx & Derived form & Gloss \\
\hline i. $0-$ & aduro $+\mathrm{y} \varepsilon$ & herb + do & - for & Oduyefo & Healer \\
\hline ii. J- & 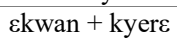 & road + show & - for & Jkwankyerefoว & Director \\
\hline iii. - & mpaebo + tie & destiny + change & - for & mpaebotiefoว & Prayer listener \\
\hline
\end{tabular}

Compounds formed out of Noun-Verb combinations usually involve affixation as well. In other words, after putting the two bases together, affixes are attached to the derived word before the derivation process is completed as depicted below:

11. $\mathrm{N} \rightarrow(\mathrm{Pfx})-$ Noun $_{\text {base }}-$ Verb $_{\text {base }}-(\mathrm{Sfx})$

12. a

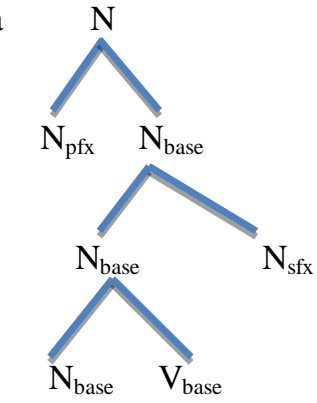

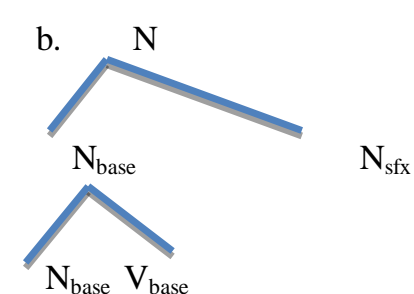

mpaebs tie $\quad$ for $\rightarrow$ mpaebotiefor

o duru $\quad$ ye $\quad$ for $\rightarrow$ Oduruyefor

The illustration in (12a) displays a N-V compounding, whereby the noun aduro 'medicine' and the verb $y \varepsilon$ 'do' are concatenated to form aduroye. This form then undergoes affixation, that is, the addition of the nominal suffix -for (an

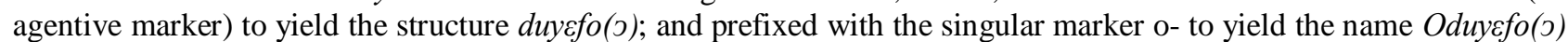
'herbalist/healer'. Simialry, in (12b), the form Mpaebstiefos 'prayer listener' is made up of the base noun mpaebJ 'prayer' and the verb tie 'listen' which then picks up the agentive marker -fo to obtain the output form. Furthermore, almost all the base nouns of this pattern are common nouns and the verbs are in the indicative mood. Appah (2003) notes that in Akan, the choice of an affix in the process of deriving a nominal is determined by certain semantic factors. These include the entity to be named; whether or not the entity is inanimate; human or non-human. As could also be seen from table 6 , during the process of nominalization, some of the constituents drop their original affixes and pick up new ones which conform to the appropriate semantic class or feature of the referent (i.e. either +human or +inanimate). In ' $\mathrm{i}$ ' for instance, the base form having gone through the process of compounding, drops the prefix -a in aduro and replaces it with o- (+human, in singular form) in the output form. A close look at the structure of the base forms suggests that originally, they are verb phrases whose linear orders have been transposed in the process of constructing the nominals. That is, we can switch the positions of the underlying constituents to ascertain the verb phrases (VPs) as portrayed in the phrase ye aduro 'to be on medication'.

\section{Deriving AHTN-G from Verb + Noun Compounds}

This is similar to what was seen above in that the compounding is formed out of a verb and a noun; however, for this process, the underlying structure of the VP is maintained. In other words, the positions of the verb and its complement are not switched. In addition, just like the N-V compounding, the nominalization process may require affixation as well (usually, a prefix). The suffixes in this context are usually empty morphs (e.g. the -e in v.) as depicted in table 7 below:

TABLE 7

AHTN-G DERIVED FROM VERB-NOUN COMPOUNDS

\begin{tabular}{|c|c|c|c|c|c|}
\hline Pfx & Base forms & Gloss & Sfx & Derived Form & Gloss \\
\hline i. a- & $\mathrm{ma}+\mathrm{nsu}$ & give + water & -0 & Amosu(o) & Giver of rain \\
\hline ii. $\mathrm{n}-$ & kata + cbo & cover + chest & -כ & Nkatabo(ว) & The Chest plate \\
\hline iii. $5-$ & kata + akyi & cover + back & $-e$ & okatakyi(e) & Valiant \\
\hline iv. a- & gye + nkwa & save + life & - & Agyenkwa & Saviour \\
\hline
\end{tabular}

The sub-lexical rule for the derivation of the names is given in 13 below:

13. N $\rightarrow$ Pfx-Verb base $_{\text {-Noun }}$ base-(Sfx)

Structurally, this is represented by $14 \mathrm{a}$ and $\mathrm{b}$ below:

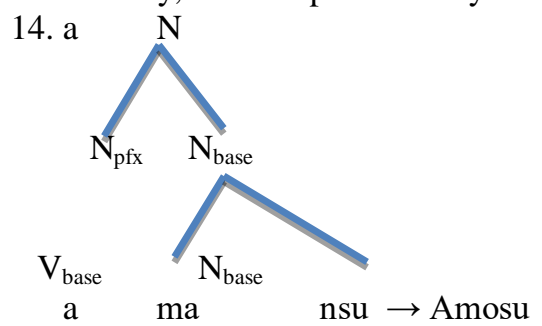

b. $\mathrm{N}$

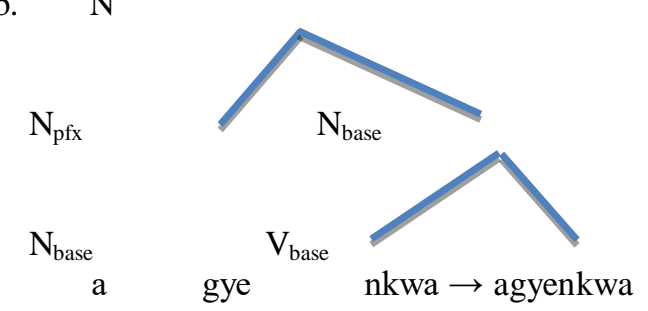


In (14a), the elements merged to form the compound nominal are the verb ma 'give' which first combines with its complement $n s u$ 'water', and then combines with the derivational prefix $a$ - to derive Amosu 'Giver of water'. The same process applies to (14b) as well.

\section{Deriving AHTN-G from Verb + Verb Compounds}

This is yet another class of compound from which some AHTN-G are composed. Here, the underlying constituents are verbs that also undergo affixation to derive the output. Examples of the names that fall within this category are outlined in Table (8) below:

TABLE 8

\begin{tabular}{|c|l|l|l|l|l|l|}
\hline \multicolumn{2}{|c|}{ Pfx } & Base forms & Gloss & Sfx & $\begin{array}{l}\text { Derived } \\
\text { Form }\end{array}$ & Gloss \\
\hline i. & o- & di + ma & intercede + give & -fo & Odimafo & Advocate \\
\hline ii. & a- & ko + be-to & go + come meet & - & Akorobsto & Everlasting \\
\hline iii. & o- & nya + mee & get + satisfy & - & Onyame & The satisfying one \\
\hline iv. & a- & ye + boa & be + help & -for & Aysboafo & The helper \\
\hline
\end{tabular}

The sub-lexical rule deduced from table 8 is given below:

15. $\mathrm{N} \rightarrow$ Pfx-Verb base $_{\text {-Verb }}$ base-(Sfx)

It should be noted that some of the outputs do not require suffixes as depicted in (iii) and (iv). Conversely, the prefixes seem to be obligatory, and they function as inflectional morphemes. Examples (i) and (v) are represented as (16 a) and (16 b) respectively.

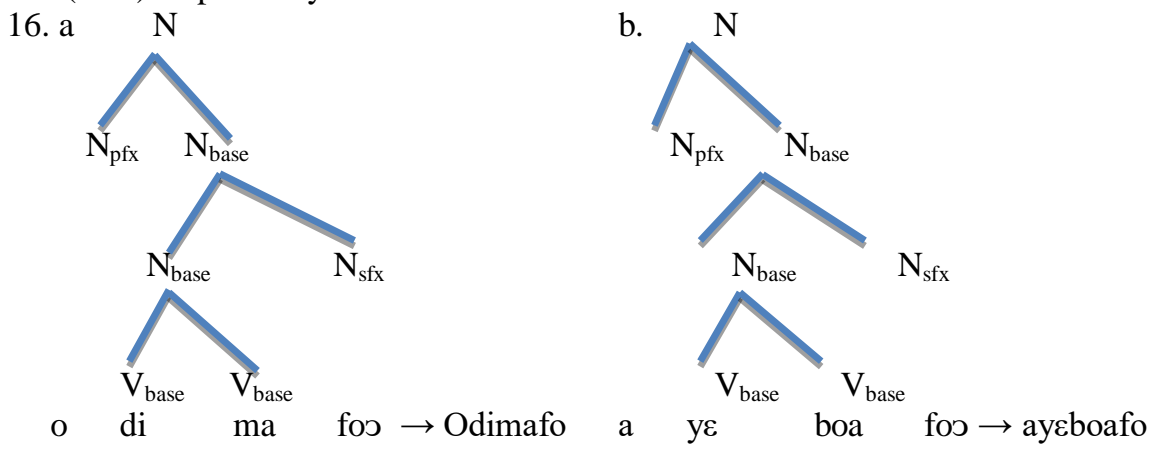

It is observed from (16a) that the verb forms $d i$ 'intercede' and $m a$ 'give' are first combined to form a complex base, then it is merged with the derivational affix to form another complex base before it merges with the inflectional affix to derive the output. The same process applies to (16b).

\section{Deriving AHTN-G from Noun + Postp. $(\mathrm{mu})+$ Noun Compounds}

In the foregoing discussion, we have concentrated on the AHTN-G derived from lexical categories (the major word classes) including verbs, nouns and adjectives. In this sub-section, we analyse some few names of God which feature a minor word class, postposition. Postpositions in Akan are equivalent to preposition in the English Language. That is, whereas prepositions occur before nouns in English, postpositions occur after nouns in Akan. The compound names under this category are formed by combining nouns and postpositions in the structure Noun + Postposition + Noun . That is, the names are composed of a noun, a postposition (usually $m u$ 'in') and another noun. Examples of such names that undergo this process are given in Table 9.

TABLE 9

AHTN-G DERIVED FROM NOUN + POSTPOSITION (MU) + NOUN

\begin{tabular}{|c|c|}
\hline Base forms & Derived form \\
\hline $\begin{array}{l}\text { i. Ahene + mu + Jhene } \\
\text { 'Kings' + 'in' + 'king' }\end{array}$ & $\begin{array}{l}\text { Ahenemuhene } \\
\text { 'King of kings' }\end{array}$ \\
\hline $\begin{array}{l}\text { ii. Awura + mu + awura(de) } \\
\text { 'lords' + 'in' + 'lord' }\end{array}$ & $\begin{array}{l}\text { Awuramuawura } \\
\text { 'Lord of Lords' }\end{array}$ \\
\hline $\begin{array}{l}\text { iii. Ahohia }+ \text { mu }+ \text { oboafor } \\
\text { 'Perplexity' + 'in' + 'helper' }\end{array}$ & $\begin{array}{l}\text { ahohiamuboafor } \\
\text { 'One who intercedes in times of distress' }\end{array}$ \\
\hline $\begin{array}{l}\text { iv. Animuonyam + mu + onimuonyamfor } \\
\text { 'glory' + 'in' + 'glorious one' }\end{array}$ & $\begin{array}{l}\text { Animuonyam-mu-nimuonyamfor } \\
\text { dignified among dignitaries' }\end{array}$ \\
\hline
\end{tabular}

The sub-lexical rule that can derive these nominals is formulated as:

17. N $\rightarrow$ Noun $_{\text {base }}$-Postp-Noun base $_{\text {. }}$.

The above rule is represented as follows: 
18. a.

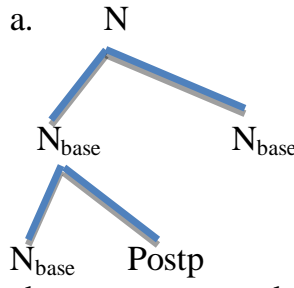

ahene $\mathrm{mu}$

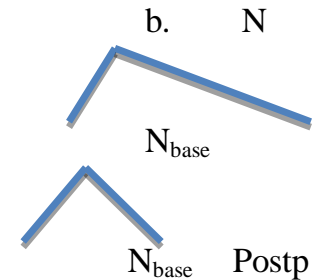

awura
$\mathrm{N}_{\text {base }}$

$\mathrm{mu}$ owura $\rightarrow$ Awuramuwura

The word structures of (18a \& b) reveal that the noun base forms ahene 'kings' and shene 'king' and awura 'lords' and owura (lord) respectively compound with the postposition $m u$ 'in' to derive the nouns Ahenemuhene 'king of kings' and Awuramuwura respectively. What happens is that, N1 first merges with the postposition to form a complex base (аһепетu and ажитати), then the base merges with N2 to derive the output. In fact, N2 is considered the head of the complex noun in that, so far as meaning is concerned, it is the one considered to be the unique or best among the rest.

Some of the compounds may be isolative, combinative or hyphenated. We have discussed the derivation of AHTN-G in combinative style. In other words, the constituents making up the nominals remain open in the resultant names. We devote the next sub-section to analyse the compound names which are in isolative style.

\section{Deriving AHTN-G with more than Two Constituents}

The names that have been considered so far under compounding process are those featuring two major word classes and postposition (N-P-N). In this sub-section, we consider those with more than two constituent parts. Sometimes compound nominals including proper names are derived from at least three underlying constituents or base forms. These nominals could therefore be considered more complex than those with two bases. A critical observation of these nominals brings to bear that their nominalization sometimes even involves a fusion of a whole or parts of a sentence or clause, hence, their complex nature which could sometimes distort their meanings. It is for this reason why their internal morphological structures must be analysed. Moreover, though they occur post-lexically (in clauses or sentences), they have morphological implications; their outputs are not clauses but nominals. Akan speakers nominalize clauses for word economy; the nominalized parts supposedly provides economic way of demonstrating the meaning of the whole clause (Mensah, 2003 cited in Appah, 2003) The morphological structures that derive the names under this category correspond to that of the traditional sentence in Akan including simple, compound and complex sentences.

\section{Deriving AHTN-G from Simple Sentences}

This is where the compound names are deduced through the nominalization of simple sentences. Here, the nominals are usually derived by dropping the subject of the sentence and combining all the remaining elements into one lexical unit in the surface form (see also Obeng, 2001; Appah, 2003). Some of the nominals may involve affixation as well. Below are some illustrations.

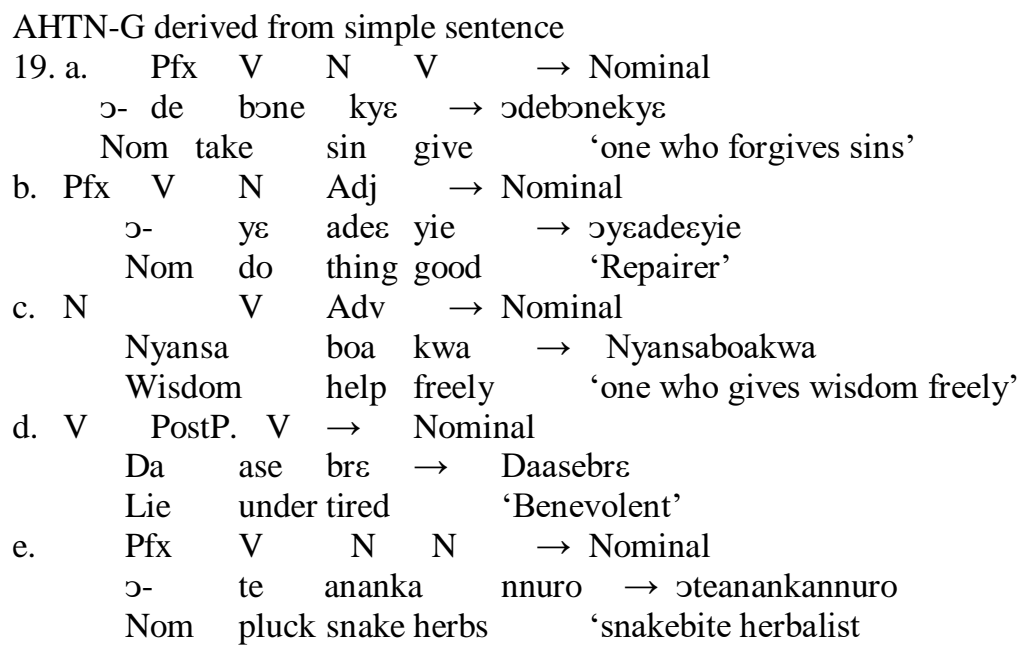

As could be seen from the data above, the derived forms are nominalized sentences or clauses. One thing worth noting is that the subjects (esp. 3SG) are dropped in the process of the derivation (Appah, 2003; Obeng, 2001). What therefore seems to be subjects in the surface realizations (e.g. ว-) are rather nominalizers. The following assertion by Appah (2003, p. 62) throws more light on this process: This is the process by which subjects both lexical and pronominal, are dropped in the process of deriving nouns from clauses. The process of subject dropping may be obscured by the presence of what looks like the pronoun on the derived noun especially when the subject in the clause from which the noun was derived was the third person singular subject pronoun $\mathrm{J}$ - 's/he'.

The examples below make the point clearer.
20. a.i. Papa no ko
de foro boכ.
a.ii. ว-ye
כkoforoboว. 
man DEF fight.HAB take climb stone 'The man climbs hills whilst fighting.'

b.i. Me-ko de foro boJ
1SG-fight.HAB take climb stone
'he climbs hills whilst fighting'
c.i Wo-ko de foro bo
2SGSUBJ-fight.HAB takes climb stone
'You climb hills whilst fighting'

3SG-be mount-climb warrior

'He is a mount-climb warrior.'

b.ii. Me-ye Jkoforoboj.

1SG-be mount-climb warrior

'I am a mount-climbing warrior.'

c.ii. Wo-ye Jkoforoboว

2SG-be mount-climb warrior

'You are a mount-climbing warrior'

It can be realized from the (22) that irrespective of the person in the (i) part of each of the sentences, the affix [ว-] will occur at (ii) part of the nominalized form. This can only imply that [כ-] is a nominalizer but not the personal pronoun (see also Kambon, 2012 for similar argument). Further, in this process, the structure SVO is compressed to VO. The subject could, however, be overtly expressed when attempt is made to reconstruct the sentences by highlighting their full forms (Appah, 2003).

\section{Deriving AHTN-G from Complex Sentences}

This is where the nominals are derived from complex sentences; sentences featuring main and subordinate clauses. The names in this category can be sub-divided into conditional and relative (compound names) based on their syntactic structures.

\section{Conditional Compounds}

This is where the clauses nominalized to derive the names are conditional. In (22) above, it was established that in deriving the nominal, the subject is dropped by default and then the elements that remain in the clause are juxtaposed to realize the surface structure representation. Here, a different case is observed. In deriving the nominals under this category, other elements (non-core) together with the subject in the deep structure are usually dropped in the output level. The nominals may or may not go through affixation. The following exemplifies this nominalization Process.

AHTN-G derived from conditional compounds

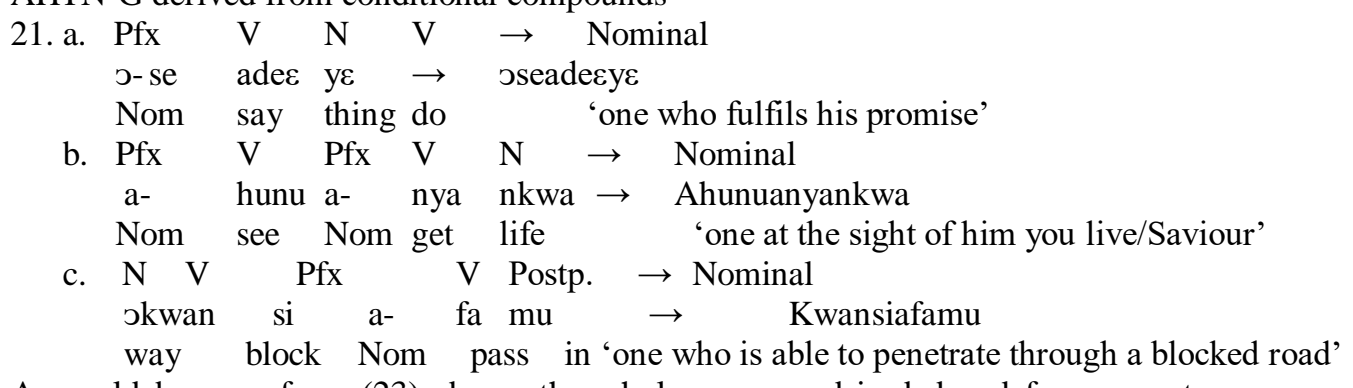

As could be seen from (23) above, the whole compound is deduced from a sentence comprising two clauses; a conditional clause and a main clause. We observe that the conditional marker is dropped during the nominalization process. Thus, in this category, it is not only the subject which undergoes dropping but also the conditional marker ' $a$ ' and some other underlying units which may not be useful in the derivational process. For example, the form Ahunuanyankwa in (b) can be a truncated or composite form of the clause:
22. Wo-hunu no a, wo-nya nkwa.
You-see him COND you-get life
'If you see him, you get life.'

As said earlier, it could be seen from the above clause that the highlighted elements including the second person singular subject wo 'you', the third person singular marker no 'him', and the conditional marker $a$ are covertly expressed in the derived nominal. The selection of the obligatory elements in the clause therefore yields; hunu+nya+nkwa (i.e. concatenation of the elements which have not been highlighted). This structure therefore undergoes affixation process to derive the form a-hunu-a-nya-nkwa Ahunuanyankwa. Here, the nominal prefix [a-] is noted to occur on both of the verbs hипи and nya simultaneously. In this light, Kambon (2012) argues that during the nominalization of clause chaining serial constructions (as in '74') in Akan, the nominalizing marker $a$ - is sometimes applied simultaneously on the verbs in the construction. The reason Kambon (2012) assigns to this is that two separate markers of perfective and nominalization cannot co-occur in that regard. They are thus said to be in complementary distribution. We take the following examples from his study to support this claim. He derives Atoapem and Abisansuamansa as follows:

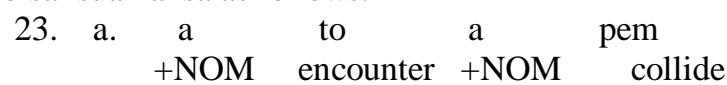

SVN: Atoapem 'unsurpassable point or thing'

(Obadele, 2012: 253)
b. a bisa nsu a ma nsa
$+\mathrm{NOM}$ ask water $+\mathrm{NOM}$ give liquor

SVN: abisansuamansa 'liberal, generous, bountiful, munificent' 
(Kambon, 2012: 235)

In '25a' above, it could be seen that the nominalizer $a$ - is applied on the verbs to and pem respectively. Similarly, in '25b' the nominalizer $a$ - has again, been respectively applied on the verbs bisa and $m a$ simultaneously.

Further, Agyekum (2019: 358) also points out that the nominal ahunиawu 'seeing and dying' is derived as:
24. [Pref V Pref V] $\rightarrow$ Nominal word
$[a-$ hunu a- wu $] \rightarrow$ Ahunuawu
[Pref see Pref die] 'powerful/fearful/dangerous/dreadful one'

Here too the nominalizer [a-] has been applied on the base verbs hunu and wu concurrently. Following these authors, it can be argued that here, the prefix $a$ - applied on the verbs simultaneously, are nominalizers rather than perfective markers.

\section{Relative Compounds}

This is the last aspect under compounding as a morphological process. It has to do with nominals that are derived from a relative clause. A nominal under this category is a product of a noun (head of NP) and a relative clause (embedded in this noun phrase) modifying NP rightwardly. Aziaku (2016) observes that in deriving Ewe animal names from a relative clause, the relative marker or pronoun which always follows its head nouns can be covertly expressed when surfaced. According to him, the animal name $x e$-do-a-ameku 'African wood owl' is for instance, derived from the relative construction below:

$\begin{array}{llll}\text { 25. } & \text { xesi do-a } & \text { ame fe ku } & \\ \text { bird } & \text { REL plant.HAB man Poss death }\end{array}$

bird that wishes humans' death

'African wood owl'

(Aziaku, 2016, p. 94)

We could see from the above construction that the relative marker si was covert in the process of deriving the name. Similarly, in Akan, the relative marker in relative constructions together with other non-core elements can drop in the nominalization process as has been exemplified below:

\section{AHTN-G Derived from Relative Compounds}

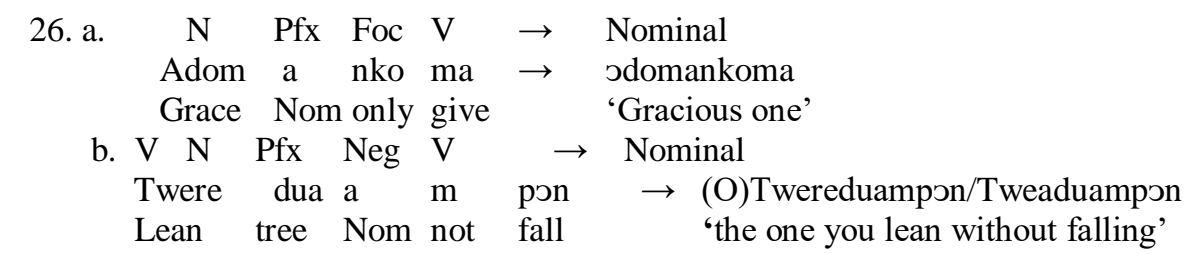

There are only two nominals that are analysed under this process. A close look at (28) above reveals that the nominal may or may not involve linear order inversion or transposition. It can be noted here that some of the nominalized forms do not stick to their linear order in the underlying representations. That is, some of the elements can swap positions during the nominalization process. For example, the form Otwereduampon can be reconstructed to have the full relative construction:

\section{Dua a wo-twere no a wo-m-pon}

Tree REL you-lean it COND you-not-fall

The tree you lean without falling

'Dependable'

In the process of nominalizing this clause, the obligatory elements (unhighlighted elements) must combine to produce the form dua-twere-m-pon. The verb or VP twere is fronted or switch positions with the NP dua 'tree' and then merge with the remaining elements m-pon yielding the form Otwereduampon also written as Tweaduampon. Here too, we see subject deletion (i.e. wo) which makes its derivation similar to that of (23) above.

Aziaku (2016) again, asserts that such linguistic swapping probably makes the patient (object) more topical than the subject NP, and also to cause a suppression to the non-core units of the structure. The process under discussion has been termed as Object Fronting by Appah (2013) and Head-Dependent Inversion by Appah (2009). We, however, observe that the derivation of the nominal in '28a' does not follow this process; the linear order remains in the surface form. For instance, sdomankoma is taken through the following processes during its production. We first write the full form as:

28.

$$
\begin{aligned}
& \text { Adom a ono nko ma } \\
& \text { Grace REL him alone give } \\
& \text { 'The grace he alone gives/the ever-gracious one' }
\end{aligned}
$$

The obligatory elements adom, nko, and ma are first concatenated (i.e. adom-nko-ma) and with the help of the nominalizing affixes $\mathrm{J}$ - and a- realized as Jdomankoma. We reiterate here that the choice of these affixes are motivated by the semantic class of the referent (i.e. thuman). Here too, the relative clause marker ' $a$ ' is in complementary distribution with the nominalizing prefix $a$ - marked on the last unit of the name; that is, nkoma. We therefore do not subscribe to the derivation of Jdomankoma by Appah (2003) which shows that the relative marker is overt in the surface structure. We tentatively argue that if it were the relative marker ' $a$ ' which is retained in the output level, it 
would have been raised or lengthened to have the form [aa] or [â] which is prototypical of relative constructions (Saah, 2010; McCracken, 2013; Abrefa, 2016).

\section{Reduplication in AHTN-G}

Dolphyne (1988: 124) defines reduplication as "a type of compound formation which consists of the repetition of the whole or part of a stem". Reduplication is of two types: partial or full, where the former has to do with a repetition of part of a stem and the latter, a complete repetition of a stem or a base. A close look at the data collected for this study also reveals such morphological properties as illustrated below:

TABLE 10

AHTN-G ASSOCIATED WITH REDUPLICATION

\begin{tabular}{|c|c|c|c|c|c|}
\hline Pfx & Base forms & Gloss & Sfx & Derived form & Gloss \\
\hline i. & borebore & dig & - & Borebore & Originator \\
\hline ii. $\quad-$ & tutu + kotwere & uproot + lean & - & Tutukotwere & Depend-able \\
\hline iii. $0-$ & twitwa + gye & cut + save & -for & Otwitwagyefo & Intercessor \\
\hline iv. - & hysbere + sesa & destiny + change & - for & Hycberesesafo & Destiny changer \\
\hline
\end{tabular}

It could be observed from the data above that the underlying constituents that contain the italic forms are the reduplicated stems; those that have been italicized are the reduplicants (copies) whereas those that have not been italicized are the original stems or bases that have been reduplicated. It can therefore be structured as:

29. $\mathrm{RF} \rightarrow$ CONSTITUENT $1_{\text {reduplicant }}$-CONSTITUENT $2_{\text {base. }}$

That is, the reduplicated form (RF) contains the constituents one (C1) and two (C2) denoting the reduplicant (Red.) and the base form respectively as has been exemplified in (83) below:

30. a

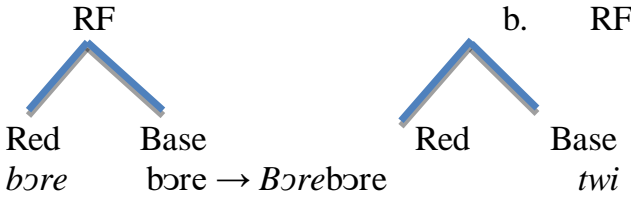

$\mathrm{RF}$

bore $\quad$ bore $\rightarrow$ Borebore $\quad$ twi $\quad$ twa $\rightarrow$ twitwa

It can be seen from (30a) that the base form has undergone a complete reduplication. That is, the base form bore, a verb, has been reduplicated to be surfaced as Borebore 'dig repeatedly' converted to imply an originator. Here, the copy (reduplicant) serves as a (nominal) prefix to the verb base (see Adomako, 2012). Also, in (30b) the first compound element has been partially reduplicated. That is, the verb base $t w a$ 'cut' has been reduplicated to derive the form twitwa 'cut repeatedly'. In this light, the first syllables twi similarly serves as prefix to the base forms twa (Adomako, 2012). From this analysis, we could observe both partial (incomplete) and complete reduplications occurring in the nominals. Further, it can be seen from the data above that in the process of the nominalization, some forms may or may not take any nominalizing affixes and so the derived forms in this category could go through affixation or not. In ' $\mathrm{i}$ ' for instance, the nominalizing affixes are covert whilst the ones (affixes) in 'iii' are overt in the composite form. Consequently, the verbs reduplicated in the nominals designate repeat actions and those which have reduplicated adjectives denote a degree of intensity. Finally, nouns reduplicated may mark number (singular/plural). The reduplicated nominals here are marking singularity.

\section{CONCLUSION}

The paper set out to investigate the morphological processes underlying Akan honorific and title names for God. It reveals that some of the names that are derived from single root morphemes are observed to be mere arbitrary tags which refer to God in metaphorical sense. Also, the study has brought to light, the morphological processes including affixation, compounding and reduplication that the names undergo. It also brought forth that mostly, the lexical categories from which the names are adduced may be verbs, adjectives, or nouns but not adverbs. Again, it can be deduced from the data analysis that the names are recursive in nature and that some of them were even derived through the nominalization of sentences or clauses which makes such names more complex, especially those under compounding. Additionally, some of the names under compounding may either be in isolative or combinative style. None of the names was observed to be a product of Adj-Noun compounds which further provides the evidence to support the claim by Appah (2013) that such a morphological pattern is not as pervasive in Akan as has been previously described. Regarding sentential names, it was noticed that most of the constructions drop their subjects in the course of nominalizing them and hence changes the SVO structure to a VO.

Moreover, in the study, it has been shown that in nominalizing relative clauses, the subject, the relativizer and other non-obligatory elements delete at the surface level. The study does not, therefore, subscribe to the claim by Appah (2003) that the relative marker is overt in the derived names. In the study, it has also been argued that some affixes which are seemingly subjects or perfective markers are not; rather, they are nominalizers. 


\section{REFERENCES}

[1] Abakah, E.N. (2003). The segmental and tone melodies of Akan. Ph.D. Dissertation. Trondheim: Norwegian University of Science \&Technology.

[2] Abakah, E.N. (2004). Elision in Fante. Africa \& Asia, 4, 181-213.

[3] Abrefa, K. B. (2016). A closer look at the Akan relativiser. Legon Journal of the Humanities, 27(1), 1-19.

[4] Adomako, K. (2012). Verbal nominalization as a derivational process: The case of Akan. Ghana Journal of Linguistics, 1(2), 43-64.

[5] Agyekum, K. (2003). Honorifics and status indexing in Akan communication. Journal of Multilingual and Multicultural Development, 24(5), 369-385.

[6] Agyekum, K. (2006). The sociolinguistics of Akan personal names. Nordic Journal of African Studies, 15(2), $206-235$.

[7] Agyekum, K. (2011). Akan kasadwini. Accra: Dwumfour publication.

[8] Agyekum, K. (2019). Akan body parts expressions: Cognitive semantics and pragmatic approach. Accra: Adwinsa Publications Ltd.

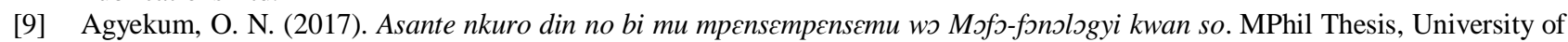
Education,

[10] Amekpordi, C. K. (2012). The sociolinguistics of the appellations in the Asogli State in the Volta Region of Ghana. MPhil Thesis. University of Ghana, Legon.

[11] Ansong, K. D, Asante, E. A. \& Kquofi, S. (2014). Eulogising God in Christian worship through Akan traditional appellation: The case of Kumasi. Advances in Social Sciences Research Journal, 1(8), 126-135.

[12] Ansu-Kyeremeh, K. (2000). Communicating nominatim: Some social aspects of Bono personal names. Research Review New Series, 16(2), 19-33.

[13] Anyidoho, A. (1991). Parallelism in Akan traditional appellation poetry. Research in African Literatures, $22(1), 67-81$.

[14] Appah, C. K. I. (2003). Nominal derivation in Akan. MPhil Thesis, NTNU, Trondheim.

[15] Appah, C. K. I. (2009). Compounding in Akan. A Paper presented at the Universals and Typology in Word- Formation, KošiceSlovakia.

[16] Appah, C. K. I. (2013). Construction morphology: Issues in Akan complex nominal morphology. Lancaster: Lancaster University Dissertation.

[17] Appah, C.K.I. (2013). The case against A-N compound in Akan. Journal of West African Languages, 40(1), 73-87.

[18] Aziaku, E. V. (2016). A linguistic analysis of animal names among the Ewe of Ghana. Köln: Rüdiger Köppe Verlag.

[19] Boadi, L. A. (1989). Praise poetry in Akan. Research in African Literatures, 20(2), 181-193.

[20] Christaller, J. G. (1933). Dictionary of the Asante and Fante Language called Twi. (2 ${ }^{\text {nd }}$ ed.). Basel: Evangelical Missionary Society.

[21] Danquah, J. B. (1968). Akan doctrine of God. Frank Cass \& Co. Ltd. London.

[22] Dolphyne, F. A. (1988). The Akan (Twi-Fante) Language. Its sound systems and tonal structure. Accra: Ghana University Press.

[23] Gyekye, K. (1996). African cultural values. Accra: Sankofa Publications.

[24] Kambon, O. B. (2012). Serial verb nominalization in Akan. Ph.D. Thesis. University of Ghana, Legon.

[25] Marfo, C. O. (2004). On tone and segmental processes in Akan phrasal words: A prosodic account. Linguistik online, 18, 93110.

[26] Mbiti, J. S. (1991). Introduction to African religion (2 ${ }^{\text {nd }}$ ed.). England: Heinemann Educational Publishers.

[27] McCracken, C. (2013). Relative clauses in Asante Twi. Rice Working Papers in Linguistics, 4, 1-28.

[28] Mensah, E. C. (2016). A morpho-semantic analysis of Mfantse neologisms in some radio stations in the Central Region. MPhil Thesis, University of Cape Coast.

[29] Obeng, S. G. (2001). African anthroponymy: An ethnopragmatic and morphophonological study of personal names in Akan and some African societies. Munich, Germany: Lincom Europa.

[30] Obeng, S. G (1997). From morphophonology to sociolinguistics: The case of Akan hypocoristic day-names. Multilingua, 16(1), 39-56.

[31] Opoku, A. (1967). Obi Kyere. Accra: Bureau of Ghana Languages.

[32] Owu-Ewie, C. (2014). A morphosyntactic analysis of some Fante habitation names (econym). The International Journal of Humanities and Social studies, 2(5), 232-243.

[33] Rattray, R. (1927). Art and religion in Ashante. Oxford University Press, London.

[34] Saah, K. K. (2010). Relative clauses in Akan. In: E.O. Aboh and J. Essegbey (Eds.), Topics in Kwa Syntax (pp. 91-107). Springer: Dordrecht.

[35] Sarpong, P. K. (1974). Ghana in retrospect. Accra: Ghana Publishing Corporation.

[36] Sarpong, P. K. (2011). Asante liturgy. Kumasi: Good Shepherded Publications.

[37] Yankah, K. (1995). Speaking for the chief: Okyeame and the politics of royal oratory. Bloomington: Indiana University Press.

Samuel Yeboah was an MPhil student in the Department of Ghanaian Languages and Linguistics, University of Cape Coast, Ghana.

Emmanuel Amo Ofori ( $\mathrm{PhD}$.) is a Senior Lecturer in the Department of Ghanaian Languages and Linguistics, University of Cape Coast, Ghana. 
Kofi Busia Abrefa (PhD.) is a Senior Lecturer in the Department of Ghanaian Languages and Linguistics, University of Cape Coast, Ghana. 